\title{
Parthenolide suppresses pancreatic cell growth by autophagy-mediated apoptosis
}

This article was published in the following Dove Press journal:

OncoTargets and Therapy

23 January 2017

Number of times this article has been viewed

\author{
Weifeng Liu' \\ Xinshuai Wang ${ }^{2}$ \\ Junjun Sun' \\ Yanhui Yang' \\ Wensheng $\mathrm{Li}^{1}$ \\ Junxin Song' \\ 'Department of Hepatobiliary Surgery, \\ ${ }^{2}$ Department of Oncology, The First \\ Affiliated Hospital, and College of \\ Clinical Medicine of Henan University \\ of Science and Technology, Luo Yang, \\ China
}

\begin{abstract}
Pancreatic cancer is an aggressive malignancy and is unresponsive to conventional chemotherapies. Parthenolide, a sesquiterpene lactone isolated from feverfew, has exhibited potent anticancer effects against various cancers. The purpose of this report was to investigate the effect and underlying mechanism of parthenolide in human pancreatic cancer Panc-1 and BxPC3 cells. The results demonstrated that parthenolide suppressed the growth and induced apoptosis of Panc-1 and BxPC3 pancreatic cancer cells with the half maximal inhibitory concentration $\left(\mathrm{IC}_{50}\right)$ ranging between 7 and $9 \mu \mathrm{M}$ after $24 \mathrm{~h}$ of treatment. Significant autophagy was induced by parthenolide treatment in pancreatic cancer cells. Parthenolide treatment concentration-dependently increased the percentage of autophagic cells and significantly increased the expression levels of p62/SQSTM1, Beclin 1, and LC3II in Panc-1 cells. Punctate LC3II staining confirmed autophagy. Furthermore, inhibiting autophagy by chloroquine, 3-methyladenine, or LC3II siRNA significantly blocked parthenolide-induced apoptosis, suggesting that parthenolide induced apoptosis through autophagy in this study. In conclusion, these studies established that parthenolide inhibits pancreatic cell growth by autophagy-mediated apoptosis. Data of the present study suggest that parthenolide can serve as a potential chemotherapeutic agent for pancreatic cancer.
\end{abstract}

Keywords: parthenolide, pancreatic cancer, autophagy, apoptosis, P62, cleaved PAPRP

\section{Introduction}

Pancreatic ductal adenocarcinoma (PDAC) is a lethal malignancy notable for its high mortality and poor prognosis, where in advanced cases patients who achieve a 5-year survival from time of diagnosis are rare $(5 \%) .{ }^{1}$ Although there have been dramatic improvements in survival over the past 3 decades for most cancers, pancreatic cancers have shown the least improvement. ${ }^{2,3}$ The antitumor effect mediated by anticancer cytotoxic agents against PDAC is very limited, and it is unlikely that chemotherapy alone will offer permanent clinical benefit for most of the PDAC patients. Thus, alternative agents are therefore urgently needed for the treatment of this disease.

Parthenolide, a sesquiterpene lactone, was first found in the medicinal plant feverfew (Tanacetum parthenium). It has been used to treat fever, headache, and arthritis for many years. ${ }^{4,5}$ Recently, it has been shown that parthenolide has an anticancer activity against a wide variety of solid tumors, such as colorectal cancer, melanoma, pancreatic cancer, breast cancer, prostate cancer, and others. ${ }^{6-9}$ Accumulated evidence indicates that parthenolide induces apoptosis by increasing oxidative stress, ${ }^{10}$ mitochondrial dysfunction, ${ }^{11}$ and inhibition of NF- $\mathrm{KB}$ activity. ${ }^{12}$ However, the detailed molecular mechanisms of anticancer effect of parthenolide in pancreatic cancer are still not fully understood; especially, the effect of parthenolide in cell pancreatic autophagy has not been reported.
Correspondence: Junxin Song Department of Hepatobiliary Surgery, The First Affiliated Hospital, and Colledge of clinical Medicine of Henan University of Science and Technology, No 24, jinghua road, Jianxi District, Luoyang 47I003, Henan Province, China Email songjunxing2016@yeah.com

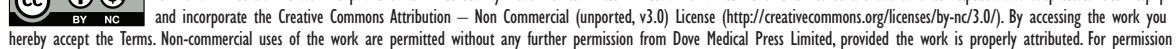
hereby accept the Terms. Non-commercial uses of the work are permitted without any further permission from Dove Med 
The present study aimed to investigate the growth suppressive effects of parthenolide on pancreatic cancer. Significant suppression of pancreatic cancer cell growth was observed by parthenolide treatment. Parthenolide also induced significant autophagy and apoptosis, which was blocked by autophagy inhibitors. This is the first report of autophagy-mediated apoptosis leading to pancreatic tumor growth suppression by parthenolide. In conclusion, parthenolide is a promising anticancer agent that is highly effective against pancreatic cancer.

\section{Materials and methods Cell culture}

Panc- 1 and BxPC3 cells were purchased from American Type Culture Collection. Panc-1 cells were cultured in Dulbecco's Modified Eagle's Medium supplemented with 10\% fetal bovine serum (FBS). BxPC3 was cultured in Roswell Park Memorial Institute 1640 (RPMI-1640) supplemented with $10 \%$ FBS. All cells were incubated at $37^{\circ} \mathrm{C}$ in a humidified atmosphere of $5 \% \mathrm{CO}_{2}$.

\section{Cell proliferation}

Thiazolyl blue tetrazolium bromide (MTT) assay was used to examine cell viability. In brief, cells were plated into 96-well culture plates $\left(8 \times 10^{3} /\right.$ well $)$. Then, the cells were exposed to indicated concentrations of parthenolide for 24 and $48 \mathrm{~h}$. After treatment, $20 \mu \mathrm{L}$ of MTT solution $(5 \mathrm{mg}$ / $\mathrm{mL}$ ) was added to each well and incubated for $4 \mathrm{~h}$. After incubation, the medium was carefully removed by aspiration. Subsequently, $200 \mu \mathrm{L}$ of dimethyl sulfoxide (DMSO) was added to each well to detect the absorbance. The absorbance of each well was measured at a wavelength of $490 \mathrm{~nm}$. All experiments were repeated at least three times. The half maximal inhibitory concentration $\left(\mathrm{IC}_{50}\right)$ values represented the concentration of vitexin required to inhibit cell viability by $50 \%$ relative to untreated cells, and were calculated by the logit method.

\section{Colony-formation assay}

Colony-formation assay was performed as follows. Briefly, single-cell suspensions of Panc-1 and BxPC3 cells were prepared and seeded in six-well tissue culture plates (500 cells/well). Then, the cells were exposed to indicated concentrations of parthenolide for 2 weeks and were fixed with methanol and stained with $0.1 \%$ crystal violet. Visible colonies were manually counted. Data shown are the means \pm standard deviation (SD) and representative of three independent experiments.

\section{Cell cycle analysis}

Panc-1 cells were seeded in six-well tissue culture plates. After $24 \mathrm{~h}$, the cells were treated with parthenolide at concentrations of $0,2.5$, and $5 \mu \mathrm{M}$ for $24 \mathrm{~h}$. Then, the cells were detached and fixed in $4 \mathrm{~mL}$ of cold $75 \%$ ethanol at $-20^{\circ} \mathrm{C}$ overnight. Subsequently, the cell pellets were incubated with $0.5 \mathrm{~mL}$ of phosphate-buffered saline (PBS) containing $100 \mu \mathrm{g} / \mathrm{mL}$ RNase (Sungene, Tianjin, China) and $5 \mu \mathrm{g} / \mathrm{mL}$ propidium iodide (Sungene) at room temperature for $30 \mathrm{~min}$. Cell cycle distribution was analyzed using Accuri C6 flow cytometer (BD Biosciences, San Jose, CA, USA).

\section{Annexin V/propidium iodide apoptosis assay}

Apoptosis assay was performed using a commercially available kit and as per manufacturer's instruction (Sungene). Approximately $0.3 \times 10^{6}$ cells were plated in each well of a six-well plate and left overnight in the incubator. Parthenolide was added in different concentrations for $24 \mathrm{~h}$. After $24 \mathrm{~h}$ of treatment, cells were harvested by trypsinization and suspended in PBS. The cells were then washed and suspended in $200 \mu \mathrm{L}$ of binding buffer. Later, $5 \mu \mathrm{L}$ Annexin-V fluorescein isothiocyanate (FITC) and $5 \mu \mathrm{L}$ of propidium iodide (PI) was added and incubated for $20 \mathrm{~min}$ in the dark. Volume was adjusted to $200 \mu \mathrm{L}$ by adding binding buffer. Samples were analyzed by flow cytometer after vortexing.

\section{GFP-light chain 3 (LC3) puncta analysis}

For transfection, cells were trypsinized and seeded in sixwell plates at a density of 5,000 cells/well. Panc-1 cells were transfected with the GFP-LC3 plasmid using Lipofectamine $3000^{\mathrm{TM}}$ (Thermo Fisher Scientifc, Waltham, MA, USA) according to the manufacturer's guidelines. Then, Panc-1 cells stably expressing GFP-LC3 were treated with parthenolide at concentrations of $0,2.5,5$, and $10 \mu \mathrm{M}$ and observed by fluorescence microscope with a $40 \times$ objective. Four GFP-LC3 puncta per cell were defined as autophagic cells. A minimum of 100 cells under each experimental condition were counted and presented as percentage of autophagic cells.

\section{Western blotting analysis}

Antibodies for CyclinD1, cleaved caspase3, cleaved PARP, Beclin, p62/SQSTM1, LC3 $\alpha$, and $\beta$-actin were purchased from Cell Signaling Technologies (Beverly, MA, USA). Whole cell lysate was prepared using radio immunoprecipitation assay (RIPA) lysis buffer in the presence of protease inhibitors. Total cell lysates were separated using $8 \%-12 \%$ 
sodium dodecyl sulfate-polyacrylamide gel electrophoresis (SDS-PAGE), transferred onto polyvinylidene fluoride (PVDF) membranes, and then detected using various primary antibodies. The antibody-antigen complexes were detected using the Chemiluminescent Horseradish Peroxidase (HRP) Substrate (Millipore, MA, USA).

\section{Immunofluorescence analysis}

Panc-1 cells were plated in a 24-well plate on a coverslip at a density of $0.1 \times 10^{6}$ cells/well and allowed to attach overnight. Attached cells were treated with $2.5 \mu \mathrm{M}$ parthenolide for an additional $24 \mathrm{~h}$. The cells were fixed with formalin and permeabilized using Triton-X100 solution. Then, 1\% bovine serum albumin (BSA) with goat serum was used for blocking, after which cells were incubated overnight with primary antibody for p62/SQSTM1 (1:200). The next day, cells were washed and incubated with AlexaFluor 488 secondary antibody (Cell signaling Technologies). After washing, DNA was counter-stained with 4',6-diamidino-2-phenylindole (DAPI) (eBioscience, Waltham, MA, USA) and images were taken using fluorescence microscope (Olympus, Center Valley, PA, USA).

\section{Inhibitor treatment}

Panc- 1 cells were plated at a density of $0.3 \times 10^{6}$ cells per well in a six-well plate. After overnight incubation, cells were pretreated for $3 \mathrm{~h}$ with $5 \mathrm{mM} 3$-methyladenine and $5 \mu \mathrm{M}$ chloroquine. 3-Methyladenine was purchased from SigmaAldrich (St Louis, MO, USA). Chloroquine diphosphate salt was purchased from MP Biomedicals, LLC (Solon, OH, USA). After pretreatment with inhibitors, cells were treated with $5 \mu \mathrm{M}$ parthenolide for $24 \mathrm{~h}$ and processed for Western blotting as explained earlier.

\section{LC3B silencing}

Panc-1 and BxPC3 cells were transfected with LC3II siRNA (Cell Signaling Technologies) using Lipofectamine 3000 TM (Invitrogen) according to the manufacturer's guidelines. Cells were transfected with $100 \mathrm{nM}$ LC3II siRNA or scrambled siRNA, and after $24 \mathrm{~h}$ post-transfection, cells were treated for additional $24 \mathrm{~h}$ with $5 \mu \mathrm{M}$ penfluridol. The cells were collected after treatment and processed for Western blot analysis as described earlier.

\section{Statistical analysis}

Prism 5.0 software was used for all the statistical analyses (GraphPad software Inc., San Diego, CA, USA). Results are represented as mean \pm SD or standard error of means. Statistical significance was analyzed using Student's $t$-test.

\section{Results}

\section{Parthenolide inhibits the proliferation of human pancreatic cancer cells}

First, the effects of parthenolide on cell viability in human Panc-1 cells and BxPC3 cells were examined by MTT assay. Treatment of Panc-1 and BxPC3 cells with varying concentrations of parthenolide resulted in significantly reduced survival of cells in a concentration and time-dependent manner. Compared with the control group, the values of cell viability were $93.2 \%, 79.7 \%, 36.9 \%$, and $15.5 \%$, when Panc-1 cells were treated with parthenolide at 2.5, 5, 10 , and $15 \mu \mathrm{M}$ for $24 \mathrm{~h}$, respectively. There was a similar effect of parthenolide on the cell viability of Panc-1 cells after $48 \mathrm{~h}$ parthenolide treatment. The values of cell viability of Panc- 1 cells were $88.7 \%, 73.7 \%, 21.9 \%$, and 9.5\% when cells were incubated with parthenolide at 2.5, 5, 10, and 15 $\mu \mathrm{M}$ for $48 \mathrm{~h}$, respectively (Figure 1B). For BxPC3 cells, the values of cellular viability were $89.1 \%, 73.7 \%, 18.2 \%$, and $9.3 \%$ compared to control cells when cells were treated with parthenolide at $2.5,5,10$, and $15 \mu \mathrm{M}$ for $24 \mathrm{~h}$, respectively; the cellular viability was $83.1 \%, 60.1 \%, 13.2 \%$, and $4.3 \%$ when cells were exposed to parthenolide at 2.5, 5, 10, and $15 \mu \mathrm{M}$ for $48 \mathrm{~h}$, respectively (Figure $1 \mathrm{C}$ ). The cell viability data demonstrate that the $\mathrm{IC}_{50}$ of parthenolide was 9 and $7.5 \mu \mathrm{M}$ in Panc- 1 cells following 24 and $48 \mathrm{~h}$ of treatment, respectively (Figure 1B). Similarly, in BxPC3 cells, $\mathrm{IC}_{50}$ was 7.5 and $6 \mu \mathrm{M}$ (Figure 1C) after 24 and $48 \mathrm{~h}$ of treatment, respectively.

Colony formation assay was used to further confirm the growth-inhibitory effects of parthenolide on pancreatic cancer cells. As shown in Figure 1D and E, the colony-forming abilities of Panc- 1 and BxPC3 cells were greatly inhibited by parthenolide in a dose-dependent manner. These results indicated that parthenolide possesses a potent growth-inhibitory effect on pancreatic cancer cells.

\section{Parthenolide regulates the cell cycle distribution of pancreatic cancer cells}

Next, the effect of parthenolide on cell cycle distribution in Panc-1 and BxPC3 cells was examined. Cell cycle analysis showed that parthenolide resulted in an obvious G1 cell cycle arrest in Panc-1 and BxPC3 cells (Figure 2A). The percentages of cells at G1 phase after incubation with parthenolide were increased to $61.1 \%(5 \mu \mathrm{M})$, from $49.2 \%$ in the control, while the percentages of Panc- 1 cells at $\mathrm{S}$ phase were decreased to $19.8 \%(5 \mu \mathrm{M})$ from $29.3 \%$ in the control. Similarly, the percentages of BxPC 3 cells at G1 phase after incubation with parthenolide were increased to $64.3 \%(5 \mu \mathrm{M})$ 
<smiles></smiles>

D
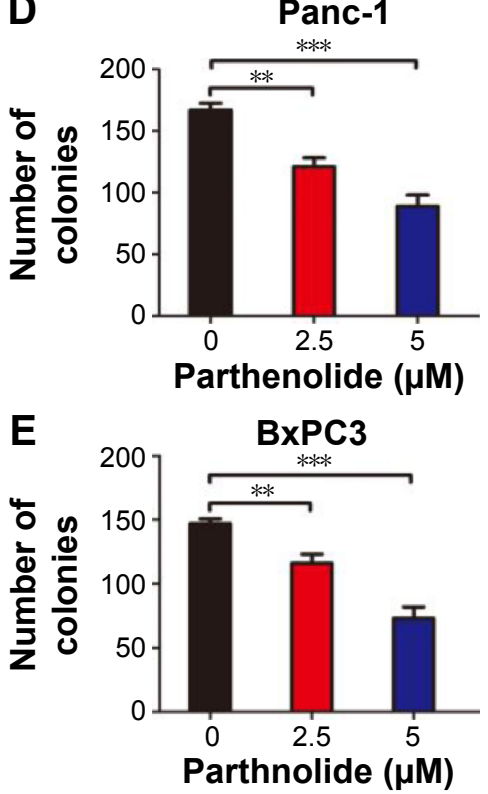
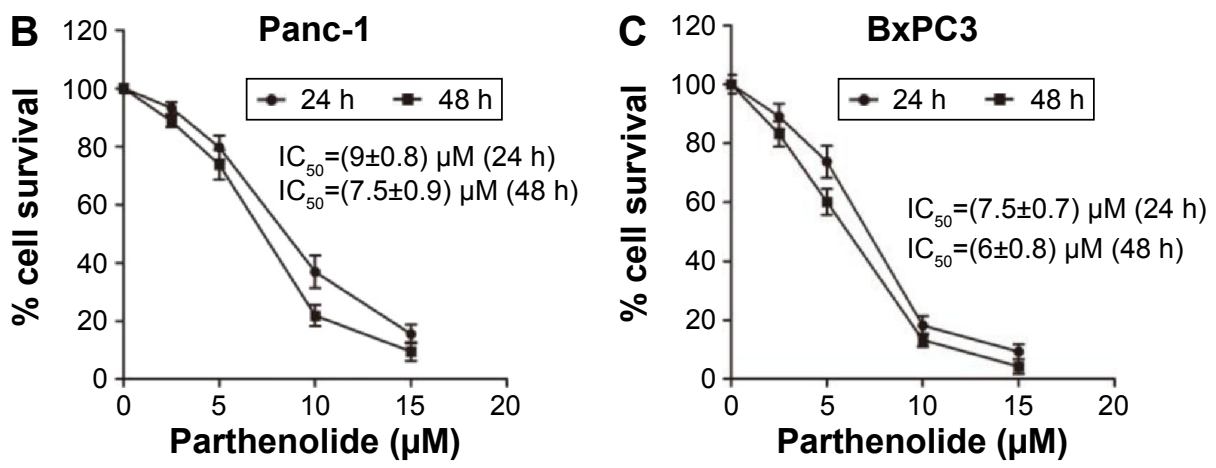
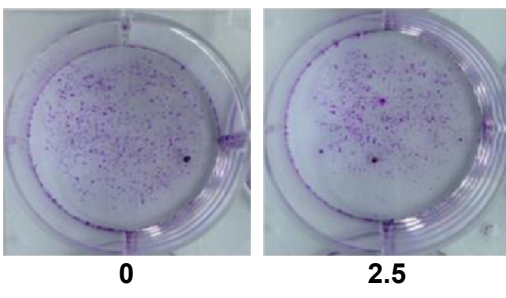

Parthenolide ( $\mu \mathrm{M})$

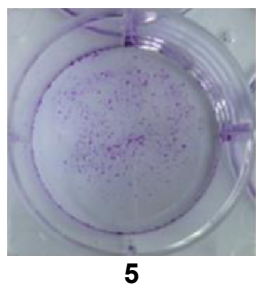

5
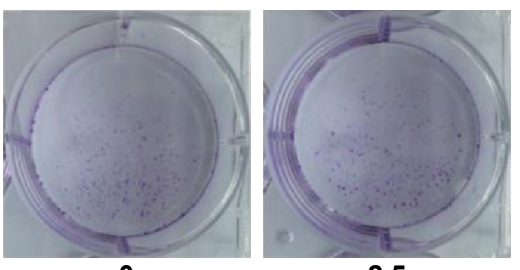

2.5

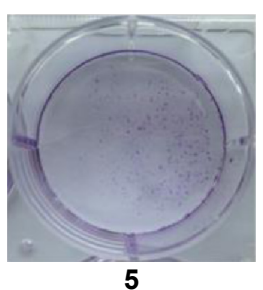

Figure I The inhibitory effects of parthenolide on human pancreatic cancer cells. (A) Chemical structure of parthenolide. (B and C) Panc-I and BxPC 3 cells were treated with different concentrations of parthenolide for 24 and $48 \mathrm{~h}$. Cell viability was measured by MTT assay to estimate IC s0 $_{\text {values. }}$ (D and $\mathbf{E}$ ) Colony formation assay showed inhibitory effect of parthenolide on Panc-I and BxPC3 cells. The experiments were performed in triplicate. Data presented as means \pm standard deviation are representative of three independent experiments. $* * P<0.01$; *** $P<0.001$.

Abbreviations: $\mathrm{IC}_{50}$, half maximal inhibitory concentration; MTT, 3-(4, 5-dimethylthiazol-2-yl)-2, 5-diphenyl tetrazolium bromide.

A

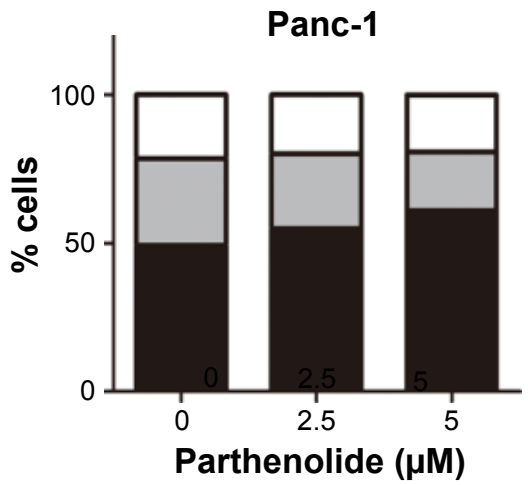

BxPC3

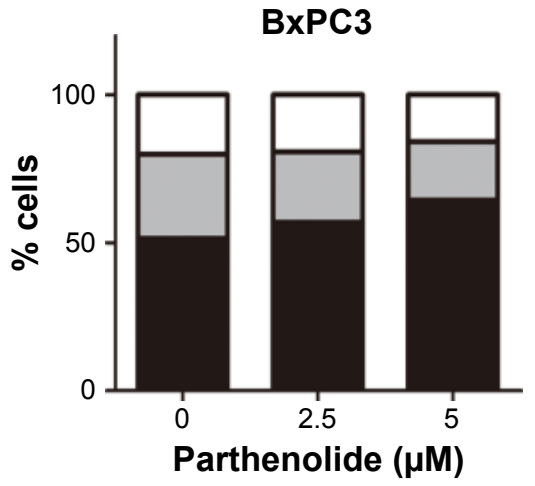

$\square$ G0/G1 phase $\square$ S phase $\square$ G2/M1 phase

B

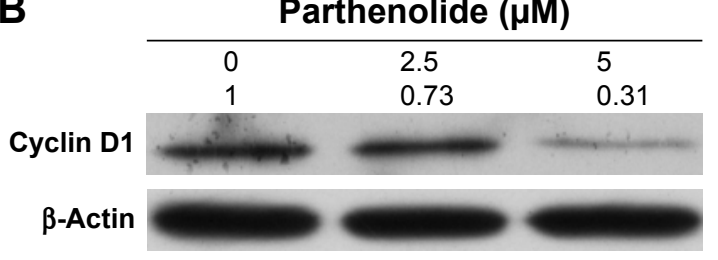

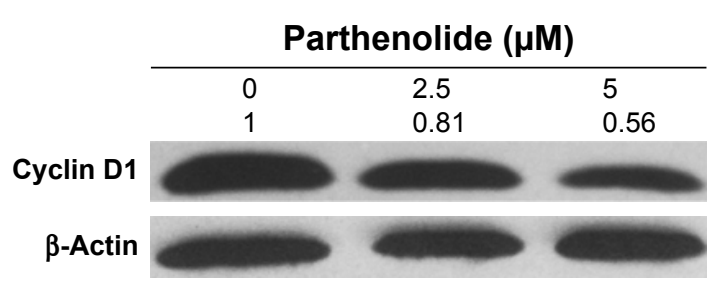


C
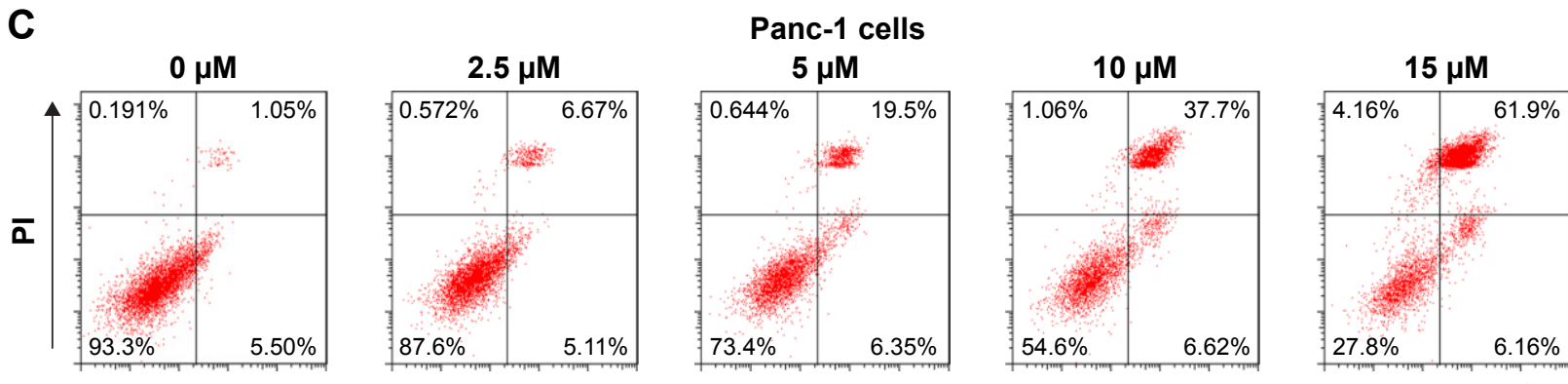

FITC
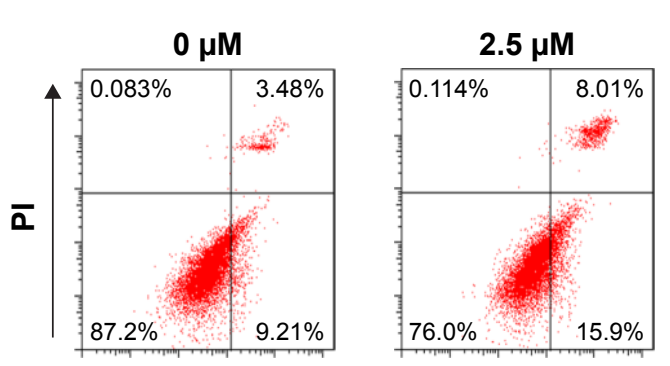

\section{BxPC3 cells}

$5 \mu \mathrm{M}$
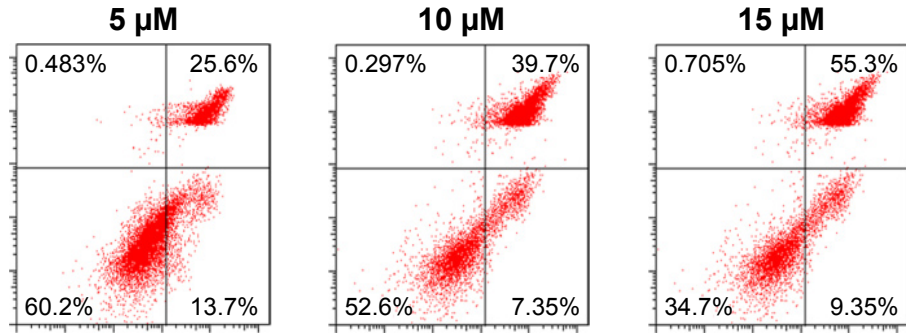

FITC

D
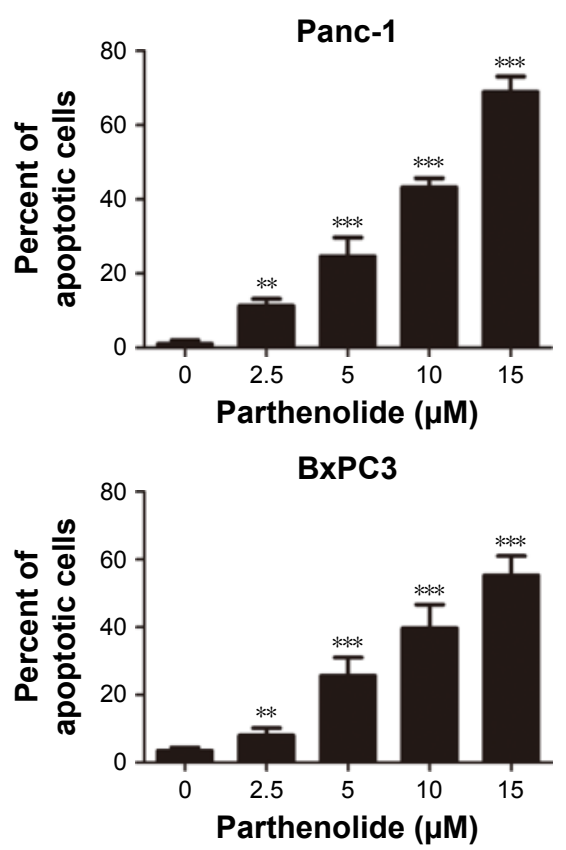

E

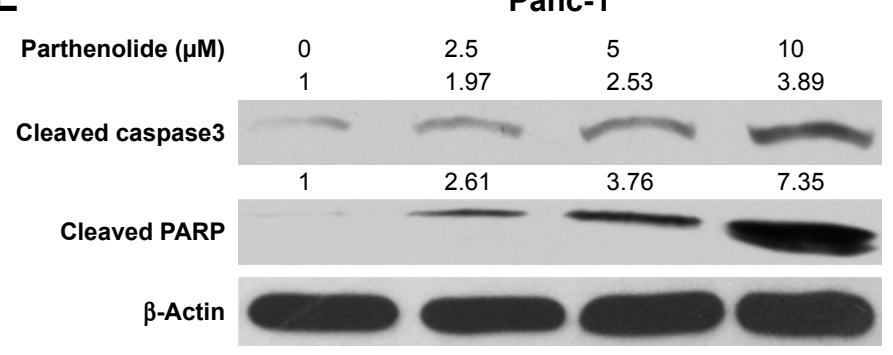

\section{BxPC3}

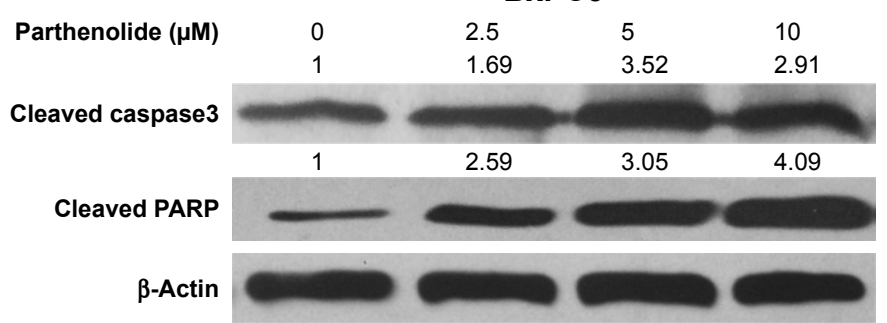

Figure 2 Parthenolide induces GI cell cycle arrest in human pancreatic cancer cells. (A) Quantification of cell number in different phases of Panc-I and BxPC3 cells treated with indicated concentrations of parthenolide $(0,2.5,5 \mu \mathrm{M})$ for $24 \mathrm{~h}$. (B) Western blotting of cyclin DI protein levels in Panc-I and BxPC3 cells treated with parthenolide for $24 \mathrm{~h}$. $\beta$-Actin served as loading control. Band intensities were quantified by Image and normalized to $\beta$-actin. Data are expressed as a fold change relative to control. (C and D) Panc-I and BxPC3 cells were treated with the indicated concentrations of PTL for $24 \mathrm{~h}$ and processed for Annexin V/PI apoptosis assay using Accuri C6 flow cytometer. The proportion of apoptotic cells was expressed as a percentage. Values were plotted as means \pm standard deviation. The experiment was repeated three times. $* * P<0.01, * * * P<0.001$ when compared with control. (E) Panc-I and BxPC3 cells were treated with varying concentrations of parthenolide for $24 \mathrm{~h}$ and processed for Western blotting. Representative blots showing concentration-dependent effect of parthenolide treatment on cleaved caspase 3 and cleaved PARP. $\beta$-Actin was used as loading control. Band intensities were quantified by Image and normalized to $\beta$-actin. Data are expressed as a fold change relative to control. This figure is the representative blots of at least three independent experiments.

Abbreviations: FITC, fluorescein isothiocyanate; PI, propidium iodide; PTL, parthenolide.

from $51.5 \%$ in the control, while the percentages of cells at $\mathrm{S}$ phase were decreased to $18.7 \%(5 \mu \mathrm{M})$ from $28.5 \%$ in the control. Since the regulatory effect of parthenolide on cell cycle distribution in Panc-1 and BxPC3 cells was found, the effect of parthenolide on the expression levels of cyclin D1 in Panc-1 and BxPC3 cells was further examined. As shown in Figure 2B, the protein level of cyclin D1 was notably decreased in Panc-1 and BxPC3 cells. The decrease 
of cyclin D1 may be associated with the G1 cell cycle arrest in parthenolide-treated pancreatic cancer cells.

\section{Induction of apoptosis by parthenolide}

This study further tested whether parthenolide could induce apoptosis in pancreatic cancer cells. Annexin V/PI apoptosis assay was performed by flow cytometry in Panc-1 and BxPC3 cells. The percent apoptosis in Panc-1 cells increased to $\sim 25 \%$ with $5 \mu \mathrm{M}$ parthenolide and to $69 \%$ with $15 \mu \mathrm{M}$ parthenolide, after $24 \mathrm{~h}$ of treatment. Similarly, the percent apoptosis in BxPC3 cells increased to $\sim 25.6 \%$ with $5 \mu \mathrm{M}$ parthenolide and to $55.3 \%$ with $15 \mu \mathrm{M}$ parthenolide, after $24 \mathrm{~h}$ of treatment (Figure 2C and D). Cleavage of caspase 3 and PARP was also observed in Panc-1 and BxPC3 cells confirming induction of apoptosis by parthenolide (Figure 2E).

\section{Parthenolide induces autophagy in pancreatic cancer cells}

Autophagy is one of the predominant programmed cell death pathways, and controversies exist on the role of autophagy in cancers. ${ }^{13-15}$ Autophagy has been shown to be induced by several anticancer agents, such as resveratrol, ${ }^{16,17}$ curcumin, ${ }^{18,19}$ genistein, ${ }^{20}$ and berberine. ${ }^{21,22}$ Thus, the effect of parthenolide on autophagy in Panc-1 cells was detected using immunofluorescence and Western blot. The formation of autophagosomes was visualized in Panc-1 cells stably expressing GFP-LC3 in the presence of parthenolide (Figure 3A), and parthenolide induced autophagy in a concentration-dependent manner in Panc-1 cells (Figure 3B). Panc-1 cells when exposed to $5 \mu \mathrm{M}$ parthenolide induced $\sim 28 \%$ autophagy. Western blot results showed substantial up-regulation of $\mathrm{LC} 3 \alpha$, a marker for the formation of autophagic vesicles, as well as enhanced expression of Beclin and p62/SQSTM1 in Panc-1 cells (Figure 3C). Autophagy induction by parthenolide was further confirmed by microscopy after staining pancreatic cancer cells with p62/SQSTM1. Immunofluorescence showed p62/SQSTM1 as represented by green staining in Panc- 1 cells after treatment with 2.5 and $5 \mu \mathrm{M}$ parthenolide for $24 \mathrm{~h}$ (Figure 4A), confirming autophagy induction by parthenolide in pancreatic cancer.

\section{Autophagy inhibitors block parthenolide- induced apoptosis}

To further delineate the mechanism of apoptosis by parthenolide treatment in pancreatic cancer cells, autophagy was inhibited by pretreatment of cells with known autophagy inhibitors like chloroquine or 3-methyladenine followed by treatment with $5 \mu \mathrm{M}$ parthenolide for $24 \mathrm{~h}$. The study observed that the growth inhibition effect of parthenolide was reversed by pretreatment with $5 \mu \mathrm{M}$ chloroquine or
A

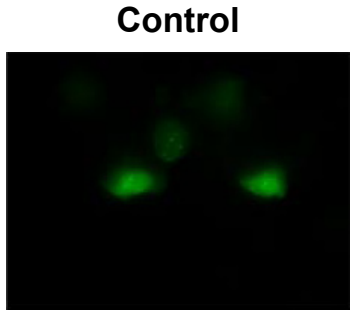

Parthenolide $2.5 \mu \mathrm{M}$

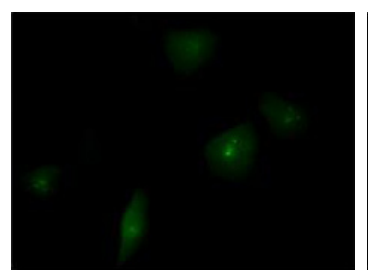

B

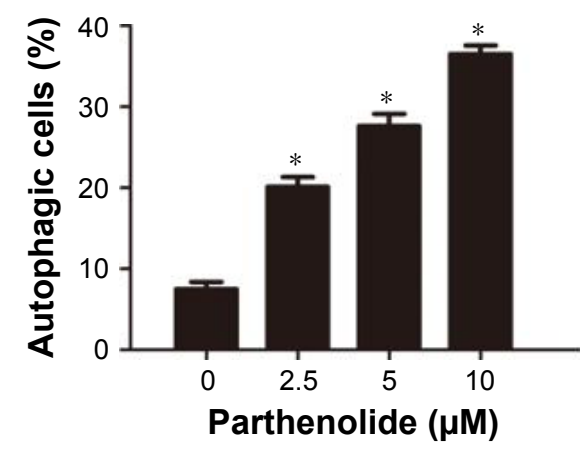

C

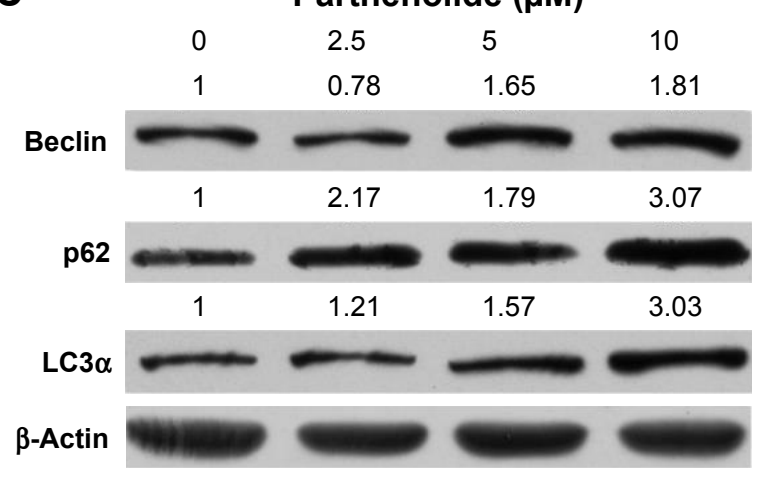

Figure 3 Induction of autophagy with parthenolide treatment. (A) Panc-I cells stably expressing GFP-LC3 were treated with indicated concentrations of parthenolide and visualized by fluorescence microscopy. (B) The autophagic cells were counted and presented as the mean values \pm standard deviation of percentage in the bar graph. (C) Panc-I cells were treated with different concentrations of parthenolide for $24 \mathrm{~h}$. Representative blots showing concentration-dependent effect of parthenolide on Beclin, p62, and LC3 $\alpha$ expressions. $\beta$-Actin was used as loading control. Band intensities were quantified by Image and normalized to $\beta$-actin. Data are expressed as a fold change relative to control. This figure is the representative blots of at least three independent experiments. $* P<0.05$ when compared to control. 
A
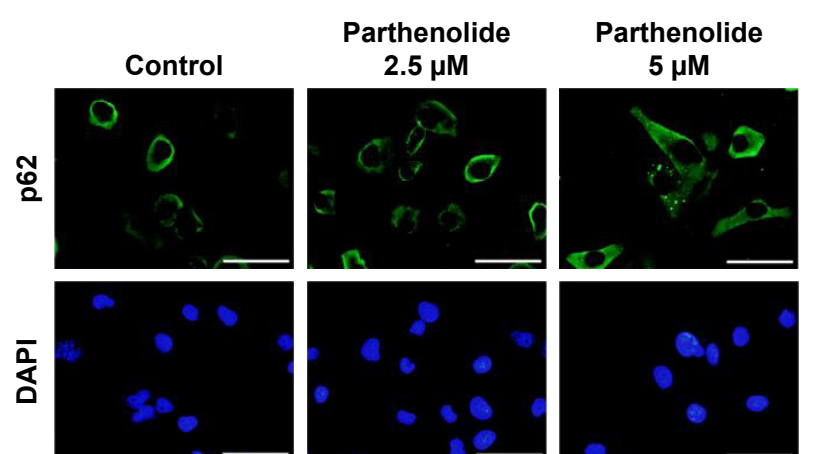

B
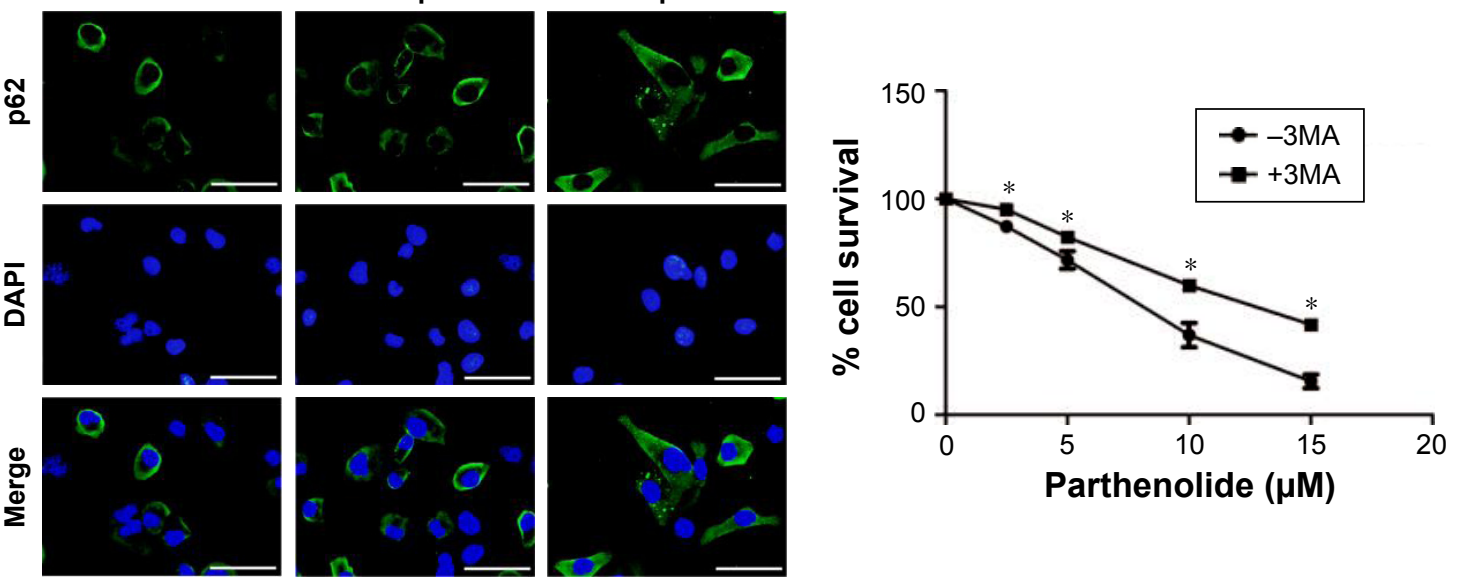

C

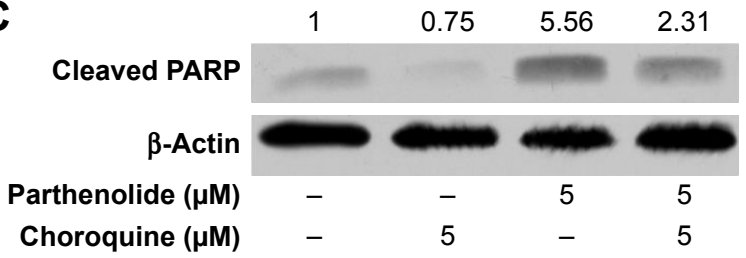

D

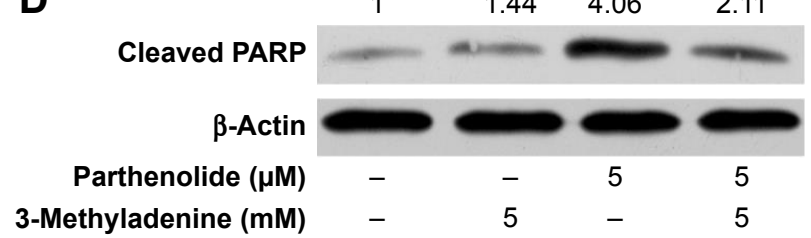

$\mathbf{E}$

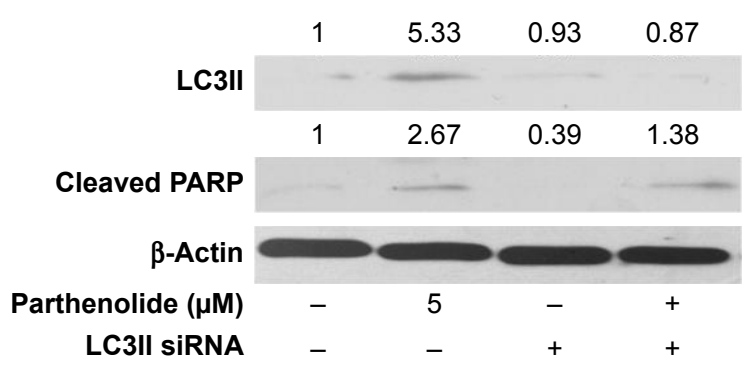

$\mathbf{F}$

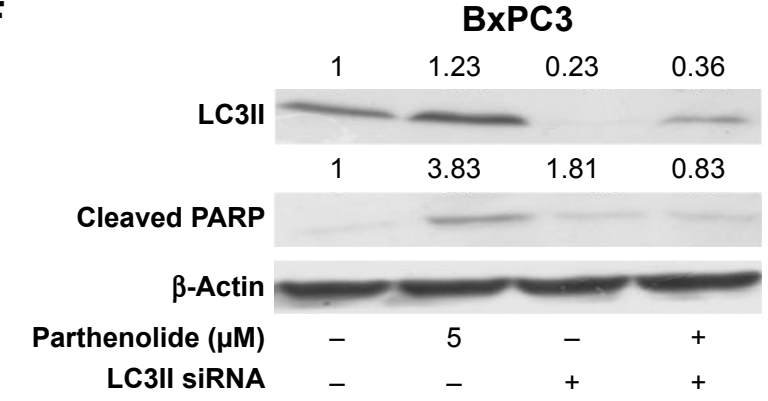

Figure 4 Parthenolide induces autophagy-mediated apoptosis. (A) Panc-I cells were plated on coverslips. Cells were treated with 2.5 and $5 \mu$ Marthenolide for 24 h. Cells were processed and mounted on slides, and images were taken using fluorescence microscopy. Green fluorescence represents p62, blue represents DAPI. Scale bars: $20 \mu \mathrm{m}$. (B) Panc-I cells were treated with indicated concentrations of parthenolide with or without 3-methyladenine for $48 \mathrm{~h}$. Cell survival was measured by MTT assay. Data presented as means \pm standard deviation are representative of three independent experiments. *Statistically significant when compared with control at $P<0.05$. Panc- $I$ cells were treated with parthenolide $(5 \mu \mathrm{M})$ for $24 \mathrm{~h}$ after $(\mathbf{C})$ cells were pretreated with $5 \mu \mathrm{M}$ chloroquine for 3 h. (D) Cells were pretreated with $5 \mu \mathrm{M} 3$-methyladenine for $3 \mathrm{~h}$. Levels of cleaved PARP were evaluated by Western blotting. $\beta$-Actin was used as loading control. (E and F) Panc-I and BxPC3 cells were transfected with LC3II siRNA. Levels of LC3II and cleaved PARP were evaluated by Western blotting. Actin was used as loading control. Band intensities were quantified by Image and normalized to $\beta$-actin. Data are expressed as a fold change relative to control.

Abbreviations: DAPI, 4',6-diamidino-2-phenylindole; MTT, 3-(4, 5-dimethylthiazol-2-yl)-2, 5-diphenyl tetrazolium bromide; 3MA, 3-methyladenine.

5 mM 3-methyladenine. In addition, blocking autophagy resulted in reduced apoptosis as indicated by less cleavage of PARP with parthenolide treatment in Panc-1 cells (Figure 4C and D). These results indicate that parthenolide treatment suppresses the growth of pancreatic cancer cells by inducing autophagy-mediated apoptosis.

\section{Silencing $\mathrm{LC} 3 \alpha$ reduces the effect of parthenolide}

To confirm the role of autophagy in parthenolide-induced apoptosis in pancreatic cancer cells, LC3 $\alpha$ was knocked down using LC $3 \alpha$ siRNA before treatment with parthenolide.
The results showed that silencing $\mathrm{LC} 3 \alpha$ reduced cleavage of PARP by parthenolide treatment in Panc-1 cells (Figure 4F). Taken together, these results confirmed that parthenolide treatment induced autophagy-mediated apoptosis in pancreatic cancer cells.

\section{Discussion}

Despite significant improvements in the technical aspects of cancer detection and management, treatment of pancreatic cancer remains a major challenge. With no effective treatments currently available, there is a pressing need for the development of novel therapeutic agents. Recently, natural 
compounds have provided an alternative resource for new anticancer drug discovery. Parthenolide, a naturally occurring compound, has been found to possess anticancer activity in various human cancers, such as breast cancer, colorectal cancer, cholangiocarcinoma, hepatoma, colorectal cancer, and pancreatic cancer. ${ }^{23-28}$ This study demonstrated the molecular mechanisms of anticancer effect of parthenolide on pancreatic cancer for the first time. It was found that parthenolide regulated cell cycle distribution through the depression of cyclin D1. It was further observed that parthenolide induced pancreatic cancer cells autophagy as evident by formation of autophagosomes and conversion of LC3A to LC3B form. Importantly, it was found that autophagy inhibitors could block parthenolide-induced apoptosis, which suggested that parthenolide suppressed the growth of pancreatic cancer cells by inducing autophagy-mediated apoptosis.

Autophagy also plays an essential role in tumor suppression and is implicated in the treatment of various diseases, due to its involvement with metabolic stress, damnification, and tumorigenesis. ${ }^{29}$ Pancreatic tumors have higher basal state autophagy as compared to other solid tumors. The results of the present study demonstrated that parthenolide treatment significantly increases the percentage of autophagic cells in Panc-1 cells in a concentration-dependent manner, as evaluated by the formation of autophagosomes. Autophagy induction with parthenolide treatment in pancreatic cancer cells was further demonstrated by Western blot and immunofluorescence. One of the hallmarks of autophagy is the accumulation of LC3II and its localization in vesicular structures. In the present study, it was observed that parthenolide treatment enhanced the expression of $\mathrm{LC} 3 \alpha$ and hence induced autophagy in pancreatic cancer cells. Our studies are in agreement with other published studies, which show that parthenolide exhibits anticancer effects by the induction of autophagy in other solid tumors. ${ }^{30-32}$ Punctate LC3II formation is an important feature associated with autophagy phenomena. Parthenolide treatment markedly increased LC3II protein levels and the number of GFP-LC3 dots compared to that obtained in controls. p62/SQSTM1 is another marker of autophagy that selectively gets incorporated into autophagosomes by directly linking to LC3II. An increase in the expression of p62/SQSTM1 with parthenolide treatment was observed in pancreatic cancer cells. Although relationship between expression of p62/SQSTM1 and autophagy is controversial, our results are in accordance with other published studies demonstrating increase in p62/SQSTM1 expression during autophagy. ${ }^{33,34}$
Interestingly, the role of autophagy in cancer cells is controversial. Several published studies demonstrated that autophagy supports survival of cancer cells. ${ }^{35}$ The US Food and Drug Administration-approved anticancer agents like gemcitabine have been shown to induce autophagy to block progression of cancer. However, tumor cells eventually get resistant to gemcitabine. ${ }^{36}$ This study demonstrated that parthenolide treatment resulted in growth suppression of pancreatic cancer in vitro and in vivo by autophagymediated apoptosis. Chloroquine and 3-methyladenine, known as early- and late-stage autophagy inhibitors, cause an increase in LC3II expression due to blocking of LC3II degradation. ${ }^{37}$ In agreement, it was observed that parthenolide treatment in combination with chloroquine or 3-methyladenine upregulated the expression of LC3II when compared to cells treated with parthenolide or inhibitors alone, indicating increased autophagic flux. Chloroquine treatment blocks the fusion between autophagosomes and lysosomes, thus inhibiting the ultimate step in autophagy. Blocking autophagy using autophagy inhibitors induced less apoptosis by parthenolide treatment in our studies. This study is in agreement with the published studies demonstrating that autophagy induction leads to suppression of cancer growth. ${ }^{38-40}$ These findings strongly support the idea that the parthenolide-induced autophagic cell death is probably an effective therapeutic strategy against pancreatic cancer.

Overall, our studies established autophagy-mediated antitumor effects of parthenolide in pancreatic cancer. This is the first report of antitumor activity of parthenolide through the induction of autophagy-mediated apoptosis in pancreatic cancer cells. Further investigations are needed to reveal the underlying mechanisms and other potential targets of parthenolide in the treatment of pancreatic cancer.

\section{Acknowledgment}

This work was supported by Foundation of He'nan Educational Committee (12A320006).

\section{Disclosure}

The authors report no conflicts of interest in this work.

\section{References}

1. Siegel RL, Miller KD, Jemal A. Cancer statistics, 2016. CA Cancer J Clin. 2016;66:7-30.

2. Guo X, Cui Z. Current diagnosis and treatment of pancreatic cancer in China. Pancreas. 2005;31:13-22.

3. Takeuchi S, Baghdadi M, Tsuchikawa T, et al. Chemotherapy-derived inflammatory responses accelerate the formation of immunosuppressive myeloid cells in the tissue microenvironment of human pancreatic cancer. Cancer Res. 2015;75:2629-2640. 
4. Knight DW. Feverfew: chemistry and biological activity. Nat Prod Rep. 1995;12:271-276.

5. Woynarowski JM, Konopa J. Inhibition of DNA biosynthesis in HeLa cells by cytotoxic and antitumor sesquiterpene lactones. Mol Pharmacol. 1981;19:97-102.

6. Zhang S, Ong CN, Shen HM. Critical roles of intracellular thiols and calcium in parthenolide-induced apoptosis in human colorectal cancer cells. Cancer Lett. 2004;208:143-153.

7. D'Anneo A, Carlisi D, Lauricella M, et al. Parthenolide induces caspaseindependent and AIF-mediated cell death in human osteosarcoma and melanoma cells. J Cell Physiol. 2013;228:952-967.

8. Liu JW, Cai MX, Xin Y, et al. Parthenolide induces proliferation inhibition and apoptosis of pancreatic cancer cells in vitro. $J$ Exp Clin Cancer Res. 2010;29:108.

9. Sun Y, St Clair D, Xu Y, Crooks PA, St Clair W. A NADPH oxidasedependent redox signaling pathway mediates the selective radiosensitization effect of parthenolide in prostate cancer cells. Cancer Res. 2010; 70:2880-2890.

10. Wen J, You KR, Lee SY, Song CH, Kim DG. Oxidative stress-mediated apoptosis. The anticancer effect of the sesquiterpene lactone parthenolide. J Biol Chem. 2002;277:38954-38964.

11. Zhang S, Ong CN, Shen HM. Involvement of proapoptotic Bcl-2 family members in parthenolide-induced mitochondrial dysfunction and apoptosis. Cancer Lett. 2004;211:175-188.

12. Garcia-Pineres AJ, Castro V, Mora G, et al. Cysteine 38 in p65/NFkappaB plays a crucial role in DNA binding inhibition by sesquiterpene lactones. J Biol Chem. 2001;276:39713-39720.

13. Wang F, Wang Q, Zhou ZW, et al. Plumbagin induces cell cycle arrest and autophagy and suppresses epithelial to mesenchymal transition involving $\mathrm{PI} 3 \mathrm{~K} / \mathrm{Akt} / \mathrm{mTOR}$-mediated pathway in human pancreatic cancer cells. Drug Des Devel Ther. 2015;9:537-560.

14. Klionsky DJ, Emr SD. Autophagy as a regulated pathway of cellular degradation. Science. 2000;290:1717-1721.

15. Yang S, Kimmelman AC. A critical role for autophagy in pancreatic cancer. Autophagy. 2011;7:912-913.

16. Scarlatti F, Maffei R, Beau I, Codogno P, Ghidoni R. Role of non-canonical Beclin 1-independent autophagy in cell death induced by resveratrol in human breast cancer cells. Cell Death Differ. 2008;15 1318-1329.

17. Ohshiro K, Rayala SK, Kondo S, et al. Identifying the estrogen receptor coactivator PELP1 in autophagosomes. Cancer Res. 2007;67: 8164-8171.

18. Kim JY, Cho TJ, Woo BH, et al. Curcumin-induced autophagy contributes to the decreased survival of oral cancer cells. Arch Oral Biol. 2012; 57:1018-1025.

19. Lee SJ, Krauthauser C, Maduskuie V, Fawcett PT, Olson JM, Rajasekaran SA. Curcumin-induced HDAC inhibition and attenuation of medulloblastoma growth in vitro and in vivo. BMC Cancer. 2011; 11:144.

20. Gossner G, Choi M, Tan L, et al. Genistein-induced apoptosis and autophagocytosis in ovarian cancer cells. Gynecol Oncol. 2007;105:23-30

21. Wang N, Feng Y, Zhu M, et al. Berberine induces autophagic cell death and mitochondrial apoptosis in liver cancer cells: the cellular mechanism. J Cell Biochem. 2010;111:1426-1436.

22. Hou Q, Tang X, Liu H, et al. Berberine induces cell death in human hepatoma cells in vitro by downregulating CD147. Cancer Sci. 2011;102: 1287-1292.

OncoTargets and Therapy

\section{Publish your work in this journal}

OncoTargets and Therapy is an international, peer-reviewed, open access journal focusing on the pathological basis of all cancers, potential targets for therapy and treatment protocols employed to improve the management of cancer patients. The journal also focuses on the impact of management programs and new therapeutic agents and protocols on
23. Zhang S, Ong CN, Shen HM. Critical roles of intracellular thiols and calcium in parthenolide-induced apoptosis in human colorectal cancer cells. Cancer Lett. 2004;208:143-153.

24. Kim JH, Liu L, Lee SO, Kim YT, You KR, Kim DG. Susceptibility of cholangiocarcinoma cells to parthenolide-induced apoptosis. Cancer Res. 2005;65:6312-6320.

25. Liu JW, Cai MX, Xin Y, et al. Parthenolide induces proliferation inhibition and apoptosis of pancreatic cancer cells in vitro. J Exp Clin Cancer Res. 2010;29:108.

26. Zhang S, Ong CN, Shen HM. Critical roles of intracellular thiols and calcium in parthenolide-induced apoptosis in human colorectal cancer cells. Cancer Lett. 2004;208:143-153.

27. Park JH, Liu L, Kim IH, Kim JH, You KR, Kim DG. Identification of the genes involved in enhanced fenretinide-induced apoptosis by parthenolide in human hepatoma cells. Cancer Res. 2005;65:2804-2814.

28. Kim JH, Liu L, Lee SO, Kim YT, You KR, Kim DG. Susceptibility of cholangiocarcinoma cells to parthenolide-induced apoptosis. Cancer Res. 2005;65:6312-6320.

29. Wang F, Wang Q, Zhou ZW, et al. Plumbagin induces cell cycle arrest and autophagy and suppresses epithelial to mesenchymal transition involving PI3K/Akt/mTOR-mediated pathway in human pancreatic cancer cells. Drug Des Devel Ther. 2015;9:537-560.

30. D'Anneo A, Carlisi D, Lauricella M, et al. Parthenolide generates reactive oxygen species and autophagy in MDA-MB231 cells. A soluble parthenolide analogue inhibits tumour growth and metastasis in a xenograft model of breast cancer. Cell Death Dis. 2013;4:e891.

31. Jeyamohan S, Moorthy RK, Kannan MK, Arockiam AJ. Parthenolide induces apoptosis and autophagy through the suppression of PI3K/ Akt signaling pathway in cervical cancer. Biotechnol Lett. 2016;38(8): $1251-1260$

32. Lan B, Wan YJ, Pan S, et al. Parthenolide induces autophagy via the depletion of 4E-BP1. Biochem Biophys Res Commun. 2015;456:434-439.

33. Bjorkoy G, Lamark T, Pankiv S, Overvatn A, Brech A, Johansen T. Monitoring autophagic degradation of p62/SQSTM1. Methods Enzymol. 2009;452:181-197.

34. Bjorkoy G, Lamark T, Brech A, et al. p62/SQSTM1 forms protein aggregates degraded by autophagy and has a protective effect on huntingtin-induced cell death. $J$ Cell Biol. 2005;171:603-614.

35. Lv X, Liu F, Shang Y, Chen SZ. Honokiol exhibits enhanced antitumor effects with chloroquine by inducing cell death and inhibiting autophagy in human non-small cell lung cancer cells. Oncol Rep. 2015;34:1289-1300.

36. Pardo R, Lo RA, Archange C, et al. Gemcitabine induces the VMP1mediated autophagy pathway to promote apoptotic death in human pancreatic cancer cells. Pancreatology. 2010;10:19-26.

37. Tanida I, Minematsu-Ikeguchi N, Ueno T, Kominami E. Lysosomal turnover, but not a cellular level, of endogenous LC3 is a marker for autophagy. Autophagy. 2005;1:84-91.

38. Lim SC, Han SI. Ursodeoxycholic acid effectively kills drug-resistant gastric cancer cells through induction of autophagic death. Oncol Rep. 2015;34:1261-1268.

39. Wang F, Wang Q, Zhou ZW, et al. Plumbagin induces cell cycle arrest and autophagy and suppresses epithelial to mesenchymal transition involving PI3K/Akt/mTOR-mediated pathway in human pancreatic cancer cells. Drug Des Devel Ther. 2015;9:537-560.

40. Yang A, Rajeshkumar NV, Wang X, et al. Autophagy is critical for pancreatic tumor growth and progression in tumors with $\mathrm{p} 53$ alterations. Cancer Discov. 2014;4:905-913.

\section{Dovepress}

patient perspectives such as quality of life, adherence and satisfaction. The manuscript management system is completely online and includes a very quick and fair peer-review system, which is all easy to use. Visit http://www.dovepress.com/testimonials.php to read real quotes from published authors. 